\title{
Needle length for epinephrine prefilled syringes in children and adolescents: Is it one inch?
}

\author{
Wiparat Manuyakorn, ${ }^{1}$ Buntita Bamrungchaowkasem, ${ }^{1}$ Nichanan Ruangwattanapaisarn, ${ }^{2}$ Wasu Kamchaisatian, ${ }^{1}$ \\ Suwat Benjaponpitak
}

\begin{abstract}
Background: Intramuscular epinephrine is the first line drug in the treatment of anaphylaxis. This study was to identify the appropriateness of 1 inch needle length for epinephrine prefilled syringes in children.

Methods: Children aged 1 month to 18 years were enrolled. Skin to muscle depth (STMD) and skin to bone depth (STBD) were measured using an ultrasonography at the mid-anterolateral thigh. A 1 inch needle was considered as being appropriate if the STBD was more than 1 inch and the STMD was less than 1 inch.

Results: Seventy five infants, 75 pre-school aged children, 75 school aged children and 147 adolescent were enrolled: 196 (52.7\%) children were male. A 1 inch needle length was appropriate for $61 \%$ of the infants, for $88 \%$ of the preschool children, for $99 \%$ of the school aged children and for $95 \%$ of the adolescents. Thigh circumference $\geq 23 \mathrm{~cm}, \mathrm{BMI} \geq 16$ $\mathrm{kg} / \mathrm{m}^{2}$ and $\mathrm{BW} \geq 6 \mathrm{~kg}$ in infants provided the sensitivity of 74\%-96\% in predicting the appropriateness of 1 inch needle. In preschool group, thigh circumference $\geq 25 \mathrm{~cm}, \mathrm{BMI} \geq 13.5 \mathrm{~kg} / \mathrm{m}^{2}$ and $\mathrm{BW} \geq 10 \mathrm{~kg}$ provided the sensitivity of $98.5-100 \%$ in predicting the appropriateness of 1 inch needle. Thigh circumference $\geq 49 \mathrm{~cm}$ in adolescents provided the sensitivity of $75 \%$ in predicting that a 1 inch needle was too short.
\end{abstract}

Conclusion: One inch needle length may not be appropriated for intramuscular injection at thigh in all children. Thigh circumference, BMI and body weight are useful for predictor for using the 1 inch needle.

Keywords: Anaphylaxis, children, epinephrine, needle length, intramuscular

\section{From:}

${ }^{1}$ Department of Pediatrics, Faculty of Medicine Ramathibodi Hospital, Mahidol University, Bangkok, Thailand

${ }^{2}$ Department of Radiology, Faculty of Medicine Ramathibodi Hospital, Mahidol University, Bangkok, Thailand

\section{Introduction}

Anaphylaxis is a serious allergic reaction that has a rapid onset and can cause fatality. The prevalence of anaphylaxis is gradually increasing worldwide. ${ }^{1-3}$ Guidelines for treatment of anaphylaxis have recommended to inject epinephrine intramuscularly at anterolateral thigh. ${ }^{4,5}$ Since it can provide the early onset and higher blood level of epinephrine than injection via subcutaneous or intramuscular at deltoid. ${ }^{6}$ In addition, those patients with a history of anaphylaxis are strongly indicated for an adrenaline auto-injector. ${ }^{4,5}$ However, epinephrine auto-injectors are unavailable or unaffordable in some developing countries. We have recently demonstrated the stability and the sterility of an epinephrine prefilled syringe for use as an alternative treatment for those patients suffering from anaphylaxis.?

\section{Corresponding author:}

Wiparat Manuyakorn

Department of Pediatrics, Faculty of Medicine Ramathibodi Hospital, Mahidol University, Bangkok, Thailand

Email: mwiparat@hotmail.com

Centers for Disease Control and Prevention (CDC) has recommended 1 inch $(2.54 \mathrm{~cm})$ needle for all thigh intramuscular injection in infants and 1-11/4 inch (2.54-3.17 $\mathrm{cm}$ ) needle for all thigh intramuscular injection in children (1-18 years) ${ }^{8}$ However, a recent study in children aged $1-6$ years have reported the over-penetration in $11 \%$ of children and under-penetration in $2 \%$ of children if 1 inch needle length was used for intramuscular injection at thigh. These authors recommended 7/8-1 inch needle length for this age group. ${ }^{9}$ The current study was to identify the appropriateness of a 1 inch needle length for epinephrine prefilled syringes and the predictors for using a 1 inch needle for epinephrine prefilled syringe in children and adolescents. 


\section{Methods}

A cross-sectional study was performed during January 2015 - June 2015 in children aged between 1 month to 18 years who visited out-patient department, the day care center at Ramathibodi hospital, Bangkok, Thailand and students from secondary schools. The inclusion criteria were children with normal body weight and height. We excluded children who have chronic disease that resulted in an abnormal growth pattern such as chronic lung disease, chronic kidney disease and cardiovascular disease. Baseline characteristic [gender, age, body weight, length/ height, body mass index (BMI), thigh circumference] were recorded. The STBD and the STMD were measured ultrasonographically with a SonoSite M-Turbo Portable Ultrasound Machine (SonoSite Inc, Washington, USA) by a single radiologist in a supine position at the midpoint between the anterior superior iliac spine and the upper pole of patella on the right thigh. ${ }^{10}$ Two measurements were taken at each site, and the mean was calculated (Figure 1). The needle length was defined as being appropriate if the needle length was more than the measured STMD and it was less than the measured STBD. The needle was defined as a too long needle if the measured STBD was equal or less than the length of the needle and the needle was defined as a too short needle if the measured STMD equal or greater than the length of the needle: $5 / 8$ inch $=1.58 \mathrm{~cm}, 1$ inch $=2.54 \mathrm{~cm}$ and $1.5 \mathrm{inch}=3.81 \mathrm{~cm}$.

The study sample size of 316 children [62 infants ( 1 month - 2 years), 45 preschool children ( $>2-5$ years), 62 school age children ( $>5-10$ years) and 147 adolescents ( $>10-18$ years)] was calculated from our pilot study on the average STBD and STMD in 40 children: 10 infants, 10 preschool-aged children, 10 school-aged children and 10 adolescents. This study was reviewed and approved by the human rights and ethic committee of Faculty of Medicine Ramathibodi Hospital, Mahidol University. All parents were informed written consent and informed written assent for children aged 7 years or older about the objective of the study.

\section{Statistical analysis}

All analyses were performed using STATA statistical software version 14 (Stata corp LP, Texus, USA). Descriptive statistical methods (median, mean and frequency) were used to analyze the demographic data. Analysis of difference between groups were performed with the chi-squared test. The continuous variables were compared using ANOVA with multiple comparisons. Correlations between the variables and the STBD or the STMD were analyzed with the Pearson correlation. Receiver operating characteristic (ROC) curves were constructed for the STBD $>25.4 \mathrm{~mm}$ and the STMD < $25.4 \mathrm{~mm}$ for each parameter (body weight, length/height, thigh circumference and BMI) to identify the most reliable parameter to predict the appropriateness of a 1 inch needle. Receiver operating characteristic (ROC) curves were also constructed for the STMD $\geq 25.4 \mathrm{~cm}$ to identify the most reliable parameter to predict the inappropriateness (too short) of a 1 inch needle.

\section{Results}

Seventy five infants, 75 pre-school aged children, 75 school aged children and 147 adolescents were enrolled. Age ranged from 1 month to 18 years, with a mean age of 8 years. There was no significant difference in sex among groups.

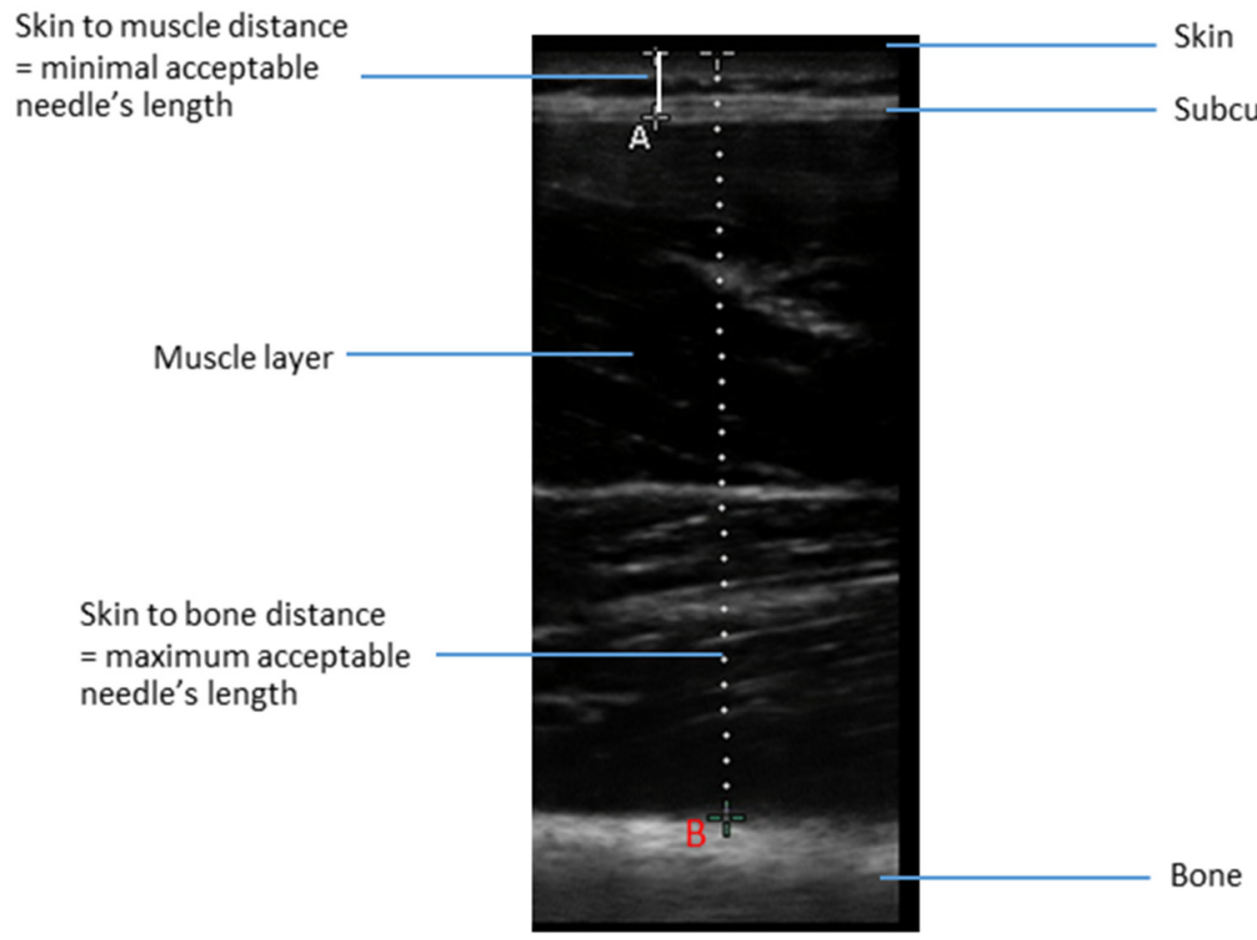

Figure 1. Ultrasound image of anterolateral thigh. A represents skin to muscle depth (STMD), B represents skin to bone depth (STBD). 
Correlation of the STBD and the STMD with thigh circumference, body mass index (BMI), body weight, and height

The STBD which can represent the maximum acceptable needle length was very strong correlated with thigh circumference $(\mathrm{R}=0.90, \mathrm{p}<0.001)$, body weight $(\mathrm{R}=0.85$, $\mathrm{p}<0.001)$, and height $(\mathrm{R}=0.82, \mathrm{p}<0.001)$ and strong correlated with body mass index (BMI) $(\mathrm{R}=0.70, \mathrm{p}<0.001)$, (Figure 2). The STMD which can represent the minimum acceptable needle length was modestly correlated with thigh circumference $(\mathrm{R}=0.27, \mathrm{p}<0.001)$, body mass index (BMI) $(\mathrm{R}=0.38, \mathrm{p}<0.001)$, and body weight $(\mathrm{R}=0.16, \mathrm{p}<0.001)$. In contrast to the STBD, height was not significantly correlated with the STMD $(R=0.08$, $\mathrm{p}=0.102)$ (Figure 3).

The appropriateness of a 1 inch needle length among age groups

To find the appropriateness for using of a 1 inch $(2.54 \mathrm{~cm})$ needle length for an epinephrine prefilled syringe, number of children who had the STBD equal or less than $2.54 \mathrm{~cm}$ (a 1 inch needle is too long) and the STMD equal or greater than $2.54 \mathrm{~cm}$ (a 1 inch needle is too short) were calculated. A 1 inch needle length was appropriate for $61.3 \%$ of the infants, for $88 \%$ of the preschool children, for $98.7 \%$ of the school aged children and for $94.6 \%$ of the adolescents. It was too long for $38.7 \%$ of the infants, for $12 \%$ of the preschool children and for $1.3 \%$ of the school aged children. However, it was too short for $5.4 \%$ of the adolescents (Table 1).

Comparison of clinical characteristics between children whom a 1 inch was appropriate and those whom a 1 inch needle was inappropriate

Sex was significantly associated with the appropriateness for a 1 inch needle in infants and adolescents. Sixty nine percent of infants whom 1 inch was not appropriate were male. In contrast, $87.5 \%$ of adolescents who were inappropriate for 1 inch needle were female. Infants and preschool children whom 1 inch needle were appropriate had a significantly higher body weight than those children whom 1 inch needle were inappropriate $(8.6 \pm 1.91 \mathrm{~kg} v s 7.32 \pm 2.32 \mathrm{~kg}, \mathrm{p} 0.02$ and $13.74 \pm$ $1.91 \mathrm{~kg} v s \quad 12.06 \pm 1.46 \mathrm{~kg}, \mathrm{p}=0.01$, respectively). No significant differences in body weight between adolescents in appropriate and inappropriate groups. Adolescents in appropriate group were significantly taller than those in inappropriate group $(159.74 \pm 9.18 \mathrm{~cm}$ vs $155.55 \pm 3.55 \mathrm{~cm}, \mathrm{p}=0.01)$. Infants and preschool children in appropriate group had a significantly higher BMI than those children in inappropriate group $\left(16.73 \pm 1.53 \mathrm{~kg} / \mathrm{m}^{2}\right.$ vs $15.66 \pm 1.17 \mathrm{~kg} / \mathrm{m}^{2}$, p 0.002 and $15.74 \pm$ $1.03 \mathrm{~kg} / \mathrm{m}^{2}$ vs $14.44 \pm 0.89 \mathrm{~kg} / \mathrm{m}^{2}, \mathrm{p}=0.001$, respectively). Infants and preschool children in appropriate group had a significantly
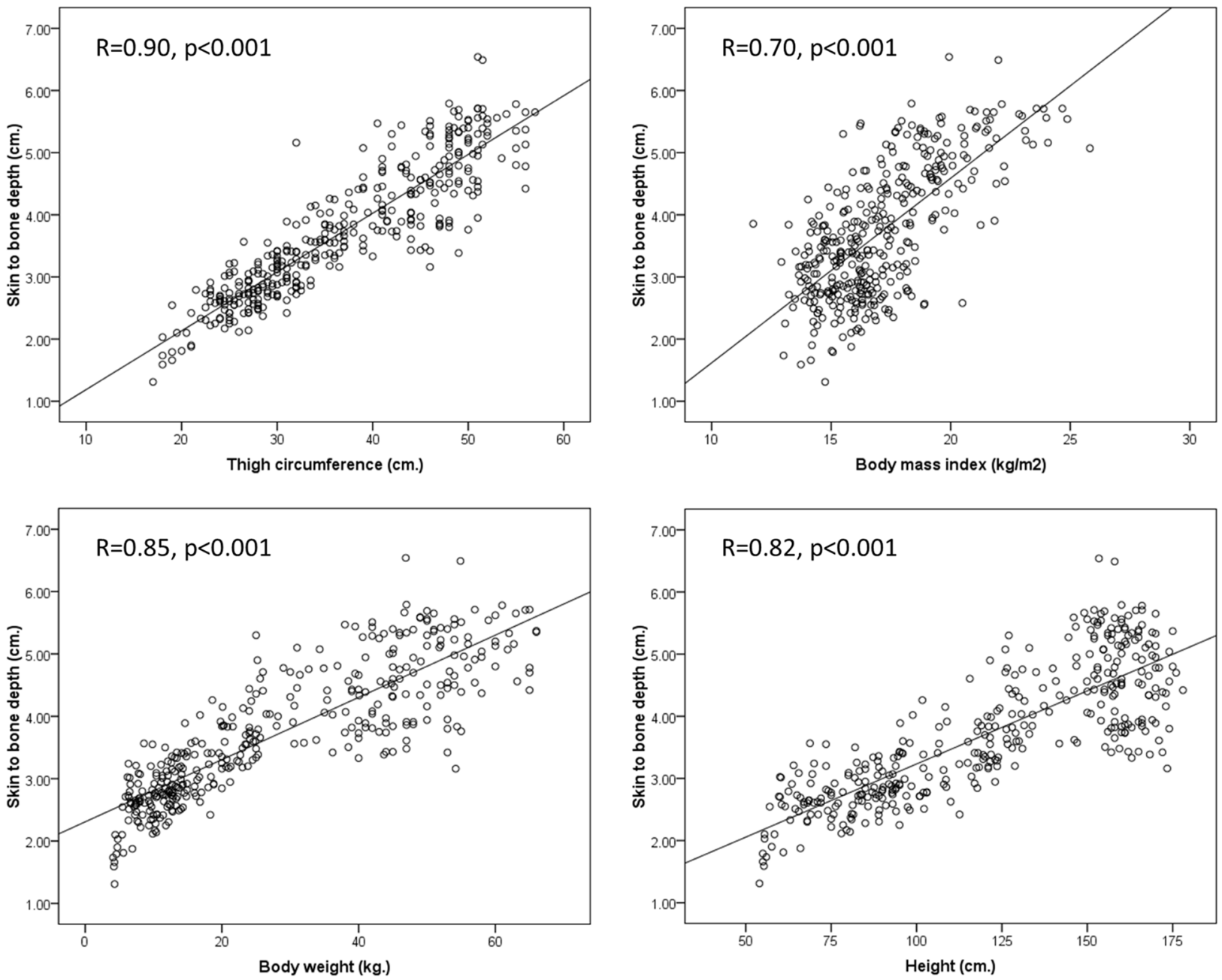

Figure 2. Correlation of skin to bone depth with thigh circumference, body mass index (BMI), body weight, and height. 

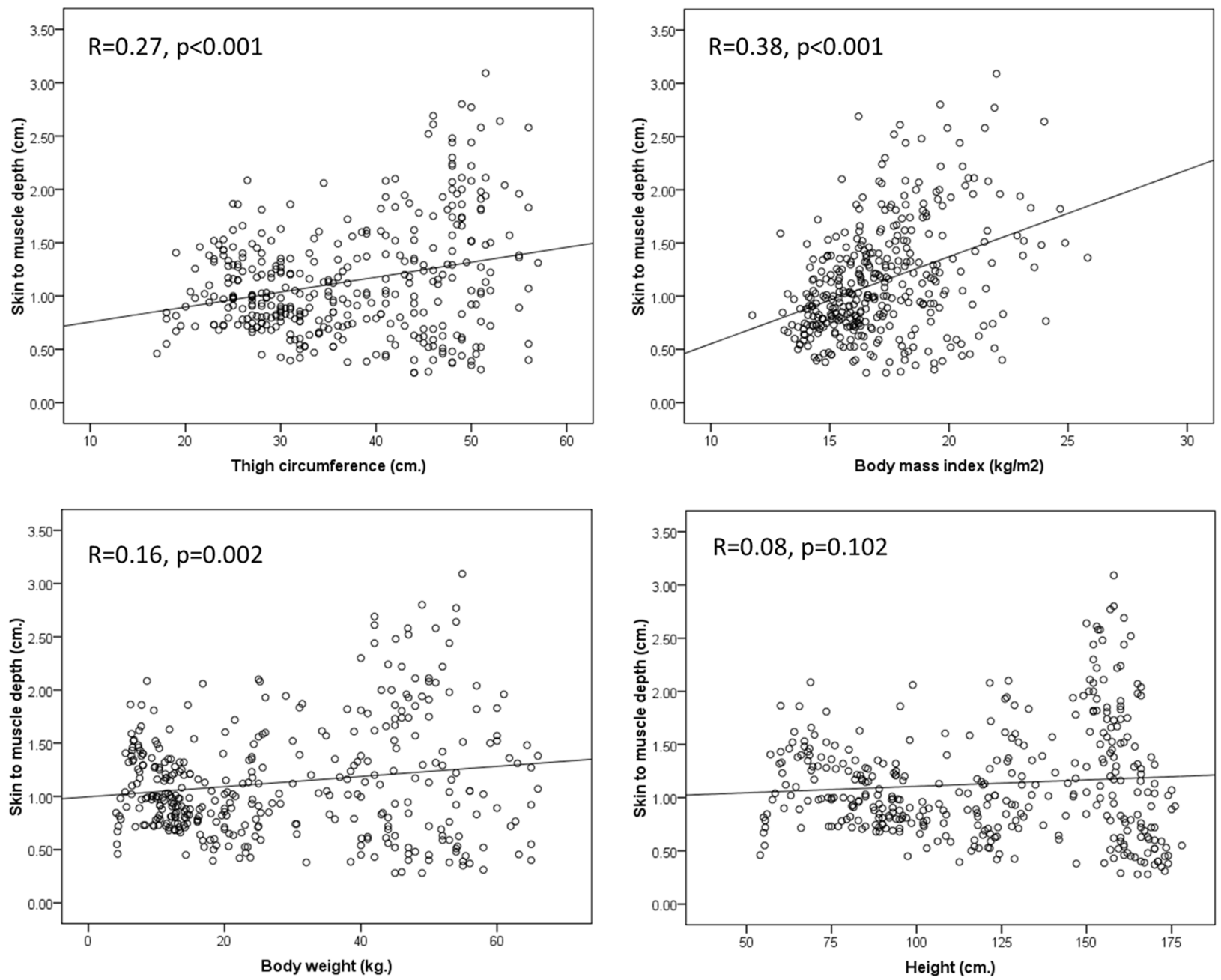

Figure 3. Correlation of skin to muscle depth with thigh circumference, body mass index (BMI), body weight, and height.

Table 1. Comparison of the appropriate rate for $5 / 8 \mathrm{inch}, 1 \mathrm{inch}$ and $1.5 \mathrm{inch}$ needle length among age groups

\begin{tabular}{|c|c|c|c|c|c|c|c|c|c|c|c|c|}
\hline \multirow{2}{*}{$\begin{array}{l}\text { Age group } \\
\text { Needle size }\end{array}$} & \multicolumn{3}{|c|}{$\begin{array}{c}\text { Infant }(1 \text { mo-2year }) \\
(n=75)\end{array}$} & \multicolumn{3}{|c|}{$\begin{array}{l}\text { Preschool }(>2-5 \text { year }) \\
\qquad(n=75)\end{array}$} & \multicolumn{3}{|c|}{$\begin{array}{l}\text { School age }(>5-10 \text { year }) \\
\qquad(n=75)\end{array}$} & \multicolumn{3}{|c|}{$\begin{array}{c}\text { Adolescent }(>10-18 \text { year }) \\
(n=147)\end{array}$} \\
\hline & $\begin{array}{l}1.58 \mathrm{~cm} \\
(5 / 8 \mathrm{in})\end{array}$ & $\begin{array}{c}2.54 \mathrm{~cm} \\
(1 \mathrm{in})\end{array}$ & $\begin{array}{l}3.81 \mathrm{~cm} \\
(1.5 \mathrm{in})\end{array}$ & $\begin{array}{l}1.58 \mathrm{~cm} \\
(5 / 8 \mathrm{in})\end{array}$ & $\begin{array}{l}2.54 \mathrm{~cm} \\
(1 \mathrm{in})\end{array}$ & $\begin{array}{l}3.81 \mathrm{~cm} \\
(1.5 \mathrm{in})\end{array}$ & $\begin{array}{l}1.58 \mathrm{~cm} \\
(5 / 8 \mathrm{in})\end{array}$ & $\begin{array}{l}2.54 \mathrm{~cm} \\
(1 \mathrm{in})\end{array}$ & $\begin{array}{l}3.81 \mathrm{~cm} \\
(1.5 \mathrm{in})\end{array}$ & $\begin{array}{l}1.58 \mathrm{~cm} \\
(5 / 8 \mathrm{in})\end{array}$ & $\begin{array}{l}2.54 \mathrm{~cm} \\
(1 \mathrm{in})\end{array}$ & $\begin{array}{l}3.81 \mathrm{~cm} \\
(1.5 \mathrm{in})\end{array}$ \\
\hline $\begin{array}{l}\text { Appropriate } \\
\text { n (\%) }\end{array}$ & $\begin{array}{c}67 \\
(89.3 \%)\end{array}$ & $\begin{array}{c}46 \\
(61.3 \%)\end{array}$ & $\begin{array}{c}0 \\
(0 \%)\end{array}$ & $\begin{array}{c}72 \\
(96 \%)\end{array}$ & $\begin{array}{c}66 \\
(88 \%)\end{array}$ & $\begin{array}{c}3 \\
(4 \%)\end{array}$ & $\begin{array}{c}63 \\
(84 \%)\end{array}$ & $\begin{array}{c}74 \\
(98.7 \%)\end{array}$ & $\begin{array}{c}35 \\
(46.7 \%)\end{array}$ & $\begin{array}{c}103 \\
(70.1 \%)\end{array}$ & $\begin{array}{c}139 \\
(94.6 \%)\end{array}$ & $\begin{array}{c}126 \\
(85.7 \%)\end{array}$ \\
\hline $\begin{array}{l}\text { Too short } \\
\text { n (\%) }\end{array}$ & $\begin{array}{c}7 \\
(9.3 \%)\end{array}$ & $\begin{array}{c}0 \\
(0 \%)\end{array}$ & $\begin{array}{c}0 \\
(0 \%)\end{array}$ & $\begin{array}{c}3 \\
(4 \%)\end{array}$ & $\begin{array}{c}0 \\
(0 \%)\end{array}$ & $\begin{array}{c}0 \\
(0 \%)\end{array}$ & $\begin{array}{c}12 \\
(16 \%)\end{array}$ & $\begin{array}{c}0 \\
(0 \%)\end{array}$ & $\begin{array}{c}0 \\
(0 \%)\end{array}$ & $\begin{array}{c}44 \\
(29.9 \%)\end{array}$ & $\begin{array}{c}8 \\
(5.4 \%)\end{array}$ & $\begin{array}{c}0 \\
(0 \%)\end{array}$ \\
\hline $\begin{array}{l}\text { Too long } \\
\text { n (\%) }\end{array}$ & $\begin{array}{c}1 \\
(1.3 \%)\end{array}$ & $\begin{array}{c}29 \\
(38.7 \%)\end{array}$ & $\begin{array}{c}75 \\
(100 \%)\end{array}$ & $\begin{array}{c}0 \\
(0 \%)\end{array}$ & $\begin{array}{c}9 \\
(12 \%)\end{array}$ & $\begin{array}{c}72 \\
(96 \%)\end{array}$ & $\begin{array}{c}0 \\
(0 \%)\end{array}$ & $\begin{array}{c}1 \\
(1.3 \%)\end{array}$ & $\begin{array}{c}40 \\
(53.3 \%)\end{array}$ & $\begin{array}{c}0 \\
(0 \%)\end{array}$ & $\begin{array}{c}0 \\
(0 \%)\end{array}$ & $\begin{array}{c}21 \\
(14.3 \%)\end{array}$ \\
\hline
\end{tabular}

longer thigh circumference than those children in inappropriate group. (25.54 $\pm 2.4 \mathrm{~cm}$ vs $22.76 \pm 3.33 \mathrm{~cm}, \mathrm{p}<0.001$ and $29.73 \pm$ $2.32 \mathrm{~cm}$ vs $26.06 \pm 2.27 \mathrm{~cm}, \mathrm{p}<0.001$, respectively). In contrast, adolescents in appropriate group had a significantly lower thigh circumference than adolescents in inappropriate group $(46.92 \pm 4.74 \mathrm{~cm}$ vs $50.31 \pm 3.39 \mathrm{~cm}, \mathrm{p}=0.05)$ (Table 2).

Comparison between the appropriate rate of a 5/8 inch needle, a 1 inch needle and $a 1.5$ inch needle length among age group

In infant group, the appropriate rate was at the highest with a 5/8 inch needle (89.7\%), followed by a 1 inch needle $(61.3 \%)$. In preschool children, similar result as infant group was demonstrated. The appropriate rate was at the highest with a $5 / 8$ inch needle (96\%), followed by a 1 inch needle $(88 \%)$. In contrast to infants and preschool children, a 1 inch needle provided the highest appropriate rate in school aged children (98.7\%), followed by a $5 / 8$ inch needle $(84 \%)$ and a 1.5 inch needle (46.7\%). The highest appropriate rate in adolescent group was demonstrated in a 1 inch needle $(94.6 \%)$, followed by a 1.5 inch needle $(85.7 \%)$ and a 5/8 inch needle (70.1\%) (Table 1). 
Table 2. Comparison in clinical characteristics between group of children whom 1 inch was appropriate and those whom 1 inch needle was inappropriate

\begin{tabular}{|c|c|c|c|c|c|c|c|c|c|}
\hline \multirow{2}{*}{$\begin{array}{c}\text { groups\# } \\
\text { appropriate }\end{array}$} & \multicolumn{3}{|c|}{ Infants $\mathrm{N}=75$} & \multicolumn{3}{|c|}{ Pre-school $N=75$} & \multicolumn{3}{|c|}{ Adolescent N=147 } \\
\hline & Yes & No & $P$-value & Yes & No & $P$-value & Yes & No & $P$-value \\
\hline Age: year, mean (SD) & $0.87(0.46)$ & $0.68(0.51)$ & 0.11 & $2.93(0.72)$ & $2.92(0.62)$ & 0.96 & $14.46(1.84)$ & $15.2(1.22)$ & 0.26 \\
\hline $\begin{array}{l}\text { Gender:N (\%) } \\
\text { Male } \\
\text { Female }\end{array}$ & $\begin{array}{l}19(41.3) \\
27(58.7)\end{array}$ & $\begin{array}{l}20(68.97) \\
9(31.03)\end{array}$ & $0.02^{*}$ & $\begin{array}{l}28(42.42) \\
38(57.78)\end{array}$ & $\begin{array}{l}4(44.44) \\
5(55.56)\end{array}$ & 1.00 & $\begin{array}{l}83(59.7) \\
56(40.7)\end{array}$ & $\begin{array}{l}1(12.5) \\
7(87.5)\end{array}$ & $0.02^{*}$ \\
\hline $\begin{array}{l}\text { Weight: kg, mean } \\
\text { (SD) }\end{array}$ & $8.6(1.91)$ & $7.37(2.38)$ & $0.02^{\star}$ & $13.74(1.91)$ & $12.06(1.46)$ & $0.01^{*}$ & $48.19(8.64)$ & $49.23(5.22)$ & 0.74 \\
\hline $\begin{array}{l}\text { Height: } \mathrm{cm} \text { mean } \\
\text { (SD) }\end{array}$ & $71.4(7.86)$ & $67.51(9.74)$ & 0.06 & $93.33(6.35)$ & $91.36(6.58)$ & 0.38 & $159.74(9.18)$ & $155.55(3.55)$ & $0.01^{*}$ \\
\hline $\begin{array}{l}\text { BMI: } \mathrm{kg} / \mathrm{m}^{2}, \text { mean } \\
\text { (SD) }\end{array}$ & $16.73(1.53)$ & $15.66(1.17)$ & $0.002^{*}$ & $15.74(1.03)$ & $14.44(0.89)$ & $0.001^{*}$ & $18.78(2.39)$ & $20.39(2.49)$ & 0.07 \\
\hline $\begin{array}{l}\text { Thigh circumference: } \\
\mathrm{cm} \text {, mean (SD) }\end{array}$ & $25.54(2.4)$ & $22.76(3.33)$ & $<0.001^{\star}$ & $29.73(2.32)$ & $26.06(2.27)$ & $<0.001^{\star}$ & $46.92(4.74)$ & $50.31(3.39)$ & $0.05^{*}$ \\
\hline
\end{tabular}

\#Data of school age children was not included in the table since 1 inch needle was not acceptable in only 1 school aged children,

* Statistical significant

Predictor for the appropriateness of a 1 inch needle for an epinephrine prefilled syringe

Receiver operating characteristic (ROC) curves were constructed for the STBD $>2.54 \mathrm{~cm}$ and the STMD $<2.54$ $\mathrm{cm}$ for each parameter (body weight, length/height, thigh circumference and BMI) to identify parameters for predicting the appropriateness of a 1 inch needle. With a body weight $\geq$ $6 \mathrm{~kg}$ (AUC: $0.72, \mathrm{p}=0.001$ ), with a thigh circumference $\geq 23$ $\mathrm{cm}$ (AUC: $0.73, \mathrm{p}=0.001$ ) and with a BMI $\geq 16 \mathrm{~kg} / \mathrm{m}^{2}$ (AUC: $0.64, \mathrm{p}=0.05)$ in infants provided the sensitivity of $74 \%$ $96 \%$ in predicting the appropriateness for a 1 inch needle. In preschool group, with a body weight $\geq 10 \mathrm{~kg}$ (AUC: $0.75, \mathrm{p}=$ 0.02 ), with a thigh circumference $\geq 25 \mathrm{~cm}$ (AUC: $0.87, \mathrm{p}<$ 0.001 ) and with a BMI $\geq 13.5 \mathrm{~kg} / \mathrm{m}^{2}$ (AUC: $0.83, \mathrm{p}=0.002$ ) provided the sensitivity of $99-100 \%$ in predicting the appropriateness for a 1 inch needle. In adolescent, ROC curves were constructed for the STMD $\geq 2.54 \mathrm{~cm}$ to identify the most reliable parameter to predict the inappropriateness (too short) of a 1 inch needle. With a thigh circumference $\geq$ $49 \mathrm{~cm}$ (AUC: $0.72, \mathrm{p}=0.04$ ) provided the sensitivity of $75 \%$ in predicting the inappropriateness (too short) of a 1 inch needle (Table 3).

Table 3. Cut off value for predicting the appropriateness and the inappropriateness of 1 inch needle

\begin{tabular}{|c|c|c|c|c|c|c|c|c|}
\hline $\begin{array}{l}\text { Weight } \\
\text { Group }\end{array}$ & Parameter & AUC & p-value & $\begin{array}{l}\text { Sensitivity } \\
\%,(95 \% \text { CI })\end{array}$ & $\begin{array}{l}\text { Specificity } \\
\%,(95 \% \text { CI })\end{array}$ & $\begin{array}{c}\text { Positive } \\
\text { predictive value } \\
(\mathrm{PPV}) \%,(95 \% \\
\mathrm{CI})\end{array}$ & $\begin{array}{c}\text { Negative } \\
\text { predictive value } \\
(\mathrm{NPV}) \%,(95 \% \\
\mathrm{CI})\end{array}$ & $\begin{array}{c}\text { Accuracy } \\
\%,(95 \% \text { CI })\end{array}$ \\
\hline \multicolumn{9}{|c|}{ Prediction for the appropriateness of 1 inch needle $(S T B D>2.54 \mathrm{~cm}$ and STMD $<2.54 \mathrm{~cm}$ ) } \\
\hline \multirow[t]{3}{*}{ Infants } & $\begin{array}{l}\text { Body weight } \\
\geq 6 \mathrm{~kg}\end{array}$ & 0.64 & 0.05 & $95.7(85.2,99.5)$ & $34.5(17.9,54.3)$ & $69.8(57,80.8)$ & $83.3(51.6,97.9)$ & $72(60.4,81.8)$ \\
\hline & $\begin{array}{l}\text { Thigh circumference } \\
\geq 23 \mathrm{~cm}\end{array}$ & 0.73 & 0.001 & $93.5(82.1,98.6)$ & $48.3(29.4,67.5)$ & $74.1(61,84.7)$ & $82.4(56.6,96.2)$ & $76(64.7,85.1)$ \\
\hline & $\begin{array}{l}\text { Body mass index } \\
\geq 16 \mathrm{~kg} / \mathrm{m}^{2}\end{array}$ & 0.72 & 0.001 & $73.9(58.9,85.7)$ & $55.2(35.7,73.6)$ & $72.3(57.4,84.4)$ & $57.1(37.2,75.5)$ & $66.7(54.8,77.1)$ \\
\hline \multirow[t]{3}{*}{ Pre-school } & $\begin{array}{l}\text { Body weight } \\
\geq 10 \mathrm{~kg}\end{array}$ & 0.75 & 0.02 & $100(94.6,100)$ & $11.1(0.3,48.2)$ & $89.2(79.8,95.2)$ & $100(2.5,100)$ & $89.3(80.1,95.3)$ \\
\hline & $\begin{array}{l}\text { Thigh circumference } \\
\geq 25 \mathrm{~cm}\end{array}$ & 0.87 & $<0.001$ & $100(94.6,100)$ & $33.3(7.5,70.1)$ & $91.7(82.7,96.9)$ & $100(29.2,100)$ & $92(83.4,97)$ \\
\hline & $\begin{array}{l}\text { Body mass index } \\
\geq 13.5 \mathrm{~kg} / \mathrm{m}^{2}\end{array}$ & 0.83 & 0.002 & $98.5(91.8,100)$ & $12.5(0.3,52.7)$ & $90.3(81,96)$ & $50(1.3,98.7)$ & $89.2(79.8,95.2)$ \\
\hline
\end{tabular}

Prediction for the inappropriateness of 1 inch needle $(S T M D \geq 2.54 \mathrm{~cm}$ )

$\begin{array}{llllllll}\text { Adolescent } & \begin{array}{l}\text { Thigh circumference } \\ \geq 49 \mathrm{~cm}\end{array} & 0.72 & 0.04 & 75(34.9,96.8) & 62.6(54,70.6) & 10.3(3.9,21.2) & 97.8(92.1,99.7)\end{array}$




\section{Discussion}

The needle length for delivering epinephrine to intramuscular tissues has previously studied for the suitable of the needle length of epinephrine auto-injectors in adult and children..$^{11-18}$ Studies in adult have shown the inadequacy of the epinephrine auto-injector needle length especially in women. ${ }^{11,13-15}$ Bhalla et al also have demonstrated that adults whom the needle length of the epinephrine auto-injector were inadequate were shorter, having higher BMI and larger thigh circumference. ${ }^{13}$ However, epinephrine auto-injectors are available only in $59.1 \%$ of countries according to a recent report from the World Allergy Organization. ${ }^{19}$ It is also unaffordable in many developing countries. Epinephrine prefilled syringes can be alternative options for anaphylaxis patients. ${ }^{20}$ In addition, the needle length of epinephrine auto-injectors range from 1.17 to $2.5 \mathrm{~cm}$ depending on the manufacturer. ${ }^{12}$ The majority of the previous studies regarding on the adequacy of the epinephrine auto-injector needle length used the needle length of Epipen ${ }^{\circ}$ as a reference. Epinephrine auto-injectors also require pressure trigger for the epinephrine delivery which produces the compression pressure on the skin resulting in the shortening the length of the STMD. As a result, studies regarding the needle length for epinephrine auto-injectors may not apply for the needle length for epinephrine prefilled syringe.

We have demonstrated that a 1 inch needle which is the recommended needle length for all thigh intramuscular injection in children was not appropriated for the epinephrine prefilled syringe in a majority of infants and preschool children. A 1 inch needle was appropriate in only $61 \%$ of the infants and $88 \%$ of the preschool children. It was too long in $39 \%$ of the infants and $12 \%$ of the preschool children. We found that a $5 / 8$ inch needle was more appropriate in these age groups. Lippert and colleagues has reported that one inch needle length was too long for intramuscular injection at thigh in $11 \%$ of children aged 1-6 years and they suggested 7/8-1 inch needle length in children aged less than 6 year. ${ }^{9}$ A study in 40 infants and 18 toddlers found subcutaneous fat thickness plus muscle thickness at thigh (equal to the STBD in our study) was less than $25.4 \mathrm{~mm}$ (1 inch) in all infants and toddlers which means that a 1 inch needle is too long for intramuscular injection at thigh. ${ }^{21}$ We have found that the male infants had a significantly lower percentage for the appropriateness for a 1 inch needle than that was demonstrated in the female infants ( $48.7 \%$ vs $75 \%, p=0.03)$. Furthermore, body weight, BMI and thigh circumference were significantly differences between infants and preschool children whom 1 inch needle were appropriate and those children with 1 inch needle inappropriate.

The association of subcutaneous fat thickness and BMI has been shown in studies in adult and children. ${ }^{11,13,17}$ We have proposed to use for a thigh circumference $\geq 23 \mathrm{~cm}$, with a BMI $\geq 16 \mathrm{~kg} / \mathrm{m}^{2}$ and with a body weight $\geq 6 \mathrm{~kg}$ for predicting the appropriateness for using 1 inch needle in infants with the sensitivity of $74-96 \%$, the positive predictive value (PPV) $70-$ $74 \%$ and negative predictive value (NPV) $57-83 \%$. We also have proposed the cut off value for preschool children: with a thigh circumference $\geq 25 \mathrm{~cm}$, with a BMI $\geq 13.5 \mathrm{~kg} / \mathrm{m}^{2}$ and with a body weight $\geq 10 \mathrm{~kg}$ as predictors for the appropriateness for using a 1 inch needle for epinephrine prefilled syringe with the sensitivity of $98-100 \%$, the positive predictive value
(PPV) of $89-92 \%$ and the negative predictive value (NPV) of $50-100 \%$. We would suggest a $5 / 8$ inch needle for preparing the epinephrine prefilled syringe in children who have one of these parameters less than these specific value for preventing intraosseous injection from the too long needle especially in male infants.

In contrast to infants and preschool children, a 1 inch needle is appropriate for almost all school age children. In addition, a 1 inch needle may be too short for intramuscular injection at thigh in adolescent especially in female. A study in adult have shown the higher STMD in female than male. ${ }^{15}$ We have proposed to use for a thigh circumference $\geq 49 \mathrm{~cm}$ as a predictor for using a needle length longer than $2.54 \mathrm{~cm}$ for preparing the epinephrine prefilled syringe in adolescent with the sensitivity of $75 \%$, the specificity of $63 \%$, the negative predictive value (NPV) of $98 \%$. The limitation of our study is that we have enrolled only children with normal growth parameters. Further studies on the STMD and the STBD in all children and adolescents are needed for the guidance for the needle length of epinephrine prefilled syringes for all children and adolescents.

In conclusion, a 1 inch needle as recommended for intramuscular injection at thigh in children and adolescents may not appropriate for using for the epinephrine prefilled syringe in all children and adolescents. It is too long for infants and preschool children and too short for female adolescents. Thigh circumference, BMI and body weigh are useful parameters for predicting the ability of using a 1 inch needle for an epinephrine prefilled syringe.

\section{Acknowledgement}

All authors have no conflict of interest. WM, BB, WK, and SB designed the study and wrote the manuscript. $\mathrm{BB}$ and NR contributed to data collection. WM and BB performed the statistical analysis and interpretation the results. All authors read and approved the final manuscripts. The authors would like to thank you Ms Dollapas Punpanich for helping in the statistical analysis. We are grateful to Berli Jucker Public Company for supporting ultrasonogram. This study was supported by a research grant from Faculty of Medicine Ramathibodi hospital, Mahidol University, Bangkok, Thailand.

\section{References}

1. Manuyakorn W, Benjaponpitak S, Kamchaisatian W, Vilaiyuk S, Sasisakulporn C, Jotikasthira W. Pediatric anaphylaxis: triggers, clinical features, and treatment in a tertiary-care hospital. Asian Pac J Allergy Immunol. 2015;33:281-8.

2. Tejedor Alonso MA, Moro Moro M, Mugica Garcia MV. Epidemiology of anaphylaxis. Clin Exp Allergy. 2015;45:1027-39.

3. Park HW. Predictors of anaphylaxis in korean adults. Allergy Asthma Immunol Res. 2015;7:1-2.

4. Lieberman P, Nicklas RA, Randolph C, Oppenheimer J, Bernstein D, Bernstein J, et al. Anaphylaxis--a practice parameter update 2015. Ann Allergy Asthma Immunol. 2015;115:341-84

5. Simons FE, Ebisawa M, Sanchez-Borges M, Thong BY, Worm M, Tanno LK, et al. 2015 update of the evidence base: World Allergy Organization anaphylaxis guidelines. World Allergy Organ J. 2015;8:32.

6. Simons FE, Gu X, Simons KJ. Epinephrine absorption in adults: intramuscular versus subcutaneous injection. J Allergy Clin Immunol. 2001;108:871-3. 
7. Kerddonfak S, Manuyakorn W, Kamchaisatian W, Sasisakulporn C, Teawsomboonkit W, Benjaponpitak S. The stability and sterility of epinephrine prefilled syringe. Asian Pac J Allergy Immunol. 2010;28:53-7.

8. Vaccine administration guidelines. In: Atkinson WWS, Hamborsky J, editors. 13th ed. Centers for Disease Control and Prevention. Epidemiology and prevention of vaccine-preventable diseases. Washington D.C. Public Health Foundation; 2015; p79-106.

9. Lippert WC, Wall EJ. Optimal intramuscular needle-penetration depth. Pediatrics. 2008;122:e556-63.

10. Manuyakorn W, Bamrungchaowkasem B, Ruangwattanapaisarn N, Kamchaisatian W, Benjaponpitak S. Optimal needle length for epinephrine prefilled syringe in children. Ann Allergy Asthma Immunol. 2017;118: 740-1 e1.

11. Johnstone J, Hobbins S, Parekh D, O’hickey S. Excess subcutaneous tissue may preclude intramuscular delivery when using adrenaline autoinjectors in patients with anaphylaxis. Allergy. 2015;70:703-6.

12. Song TT, Lieberman P. Epinephrine auto-injector needle length: what is the ideal length? Curr Opin Allergy Clin Immunol. 2016;16:361-5.

13. Bhalla MC, Gable BD, Frey JA, Reichenbach MR,Wilber ST. Predictors of epinephrine autoinjector needle length inadequacy. Am J Emerg Med. 2013;31:1671-6.

14. Tsai G, Kim L, Nevis IF, Dominic A, Potts R, Chiu J, et al. Auto-injector needle length may be inadequate to deliver epinephrine intramuscularly in women with confirmed food allergy. Allergy Asthma Clin Immunol. 2014;10:39.
15. Song TT, Nelson MR, Chang JH, Engler RJ, Chowdhury BA. Adequacy of the epinephrine autoinjector needle length in delivering epinephrine to the intramuscular tissues. Ann Allergy Asthma Immunol. 2005;94:539-42.

16. Dreborg S, Wen X, Kim L, Tsai G, Nevis I, Potts R, et al. Do epinephrine auto-injectors have an unsuitable needle length in children and adolescents at risk for anaphylaxis from food allergy? Allergy Asthma Clin Immunol. 2016;12:11.

17. Stecher D, Bulloch B, Sales J, Schaefer C, Keahey L. Epinephrine auto -injectors: is needle length adequate for delivery of epinephrine intramuscularly? Pediatrics. 2009;124:65-70.

18. Kim L, Nevis IF, Tsai G, Dominic A, Potts R, Chiu J, et al. Children under $15 \mathrm{~kg}$ with food allergy may be at risk of having epinephrine auto-injectors administered into bone. Allergy Asthma Clin Immunol. 2014;10:40.

19. Simons FE. World Allergy O. Epinephrine auto-injectors: first-aid treatment still out of reach for many at risk of anaphylaxis in the community. Ann Allergy Asthma Immunol. 2009;102:403-9.

20. Pepper AN, Westermann-Clark E, Lockey RF. The High Cost of Epinephrine Autoinjectors and Possible Alternatives. J Allergy Clin Immunol Pract. Forthcoming 2017.

21. Groswasser J, Kahn A, Bouche B, Hanquinet S, Perlmuter N, Hessel L. Needle length and injection technique for efficient intramuscular vaccine delivery in infants and children evaluated through an ultrasonographic determination of subcutaneous and muscle layer thickness. Pediatrics. 1997;100:400-3. 